\title{
Lateral variations in the crustal structure of the Indo-Eurasian collision zone
}

\author{
Amy Gilligan ${ }^{1,2}$ and Keith Priestley ${ }^{2}$ \\ ${ }^{1}$ School of Geoscience, University of Aberdeen, Aberdeen AB24 3FX,UK. E-mail: amy.gilligan@abdn.ac.uk \\ ${ }^{2}$ Bullard Laboratories, University of Cambridge, Cambridge CB3 0EZ, UK
}

Accepted 2018 April 22. Received 2018 April 11; in original form 2017 October 20

\begin{abstract}
SUMMAR Y
The processes involved in continental collisions remain contested, yet knowledge of these processes is crucial to improving our understanding of how some of the most dramatic features on the Earth have formed. As the largest and highest orogenic plateau on the Earth today, Tibet is an excellent natural laboratory for investigating collisional processes. To understand the development of the Tibetan Plateau, we need to understand the crustal structure beneath both Tibet and the Indian Plate. Building on previous work, we measure new group velocity dispersion curves using data from regional earthquakes (4424 paths) and ambient noise data (5696 paths), and use these to obtain new fundamental mode Rayleigh wave group velocity maps for periods from 5 to $70 \mathrm{~s}$ for a region including Tibet, Pakistan and India. The dense path coverage at the shortest periods, due to the inclusion of ambient noise measurements, allows features of up to $100 \mathrm{~km}$ scale to be resolved in some areas of the collision zone, providing one of the highest resolution models of the crust and uppermost mantle across this region. We invert the Rayleigh wave group velocity maps for shear wave velocity structure to $120 \mathrm{~km}$ depth and construct a 3-D velocity model for the crust and uppermost mantle of the Indo-Eurasian collision zone. We use this 3-D model to map the lateral variations in the crust and in the nature of the crust-mantle transition (Moho) across the Indo-Eurasian collision zone. The Moho occurs at lower shear velocities below northeastern Tibet than it does beneath western and southern Tibet and below India. The east-west difference across Tibet is particularly apparent in the elevated velocities observed west of $84^{\circ} \mathrm{E}$ at depths exceeding $90 \mathrm{~km}$. This suggests that Indian lithosphere underlies the whole of the Plateau in the west, but possibly not in the east. At depths of $20-40 \mathrm{~km}$ our crustal model shows the existence of a pervasive mid-crustal low velocity layer $\left(\sim 10 \%\right.$ decrease in velocity, $\left.V_{\mathrm{s}}<3.4 \mathrm{~km} \mathrm{~s}^{-1}\right)$ throughout all of Tibet, as well as beneath the Pamirs, but not below India. The thickness of this layer, the lowest velocity in the layer and the degree of velocity reduction vary across the region. Combining our Rayleigh wave observations with previously published Love wave dispersion measurements, we find that the low velocity layer has a radial anisotropic signature with $V_{\mathrm{sh}}>V_{\mathrm{sv}}$. The characteristics of the low velocity layer are supportive of deformation occurring through ductile flow in the mid-crust.
\end{abstract}

Key words: Asia; Tomography; Crustal imaging; Surface waves and free oscillations; Continental tectonics: compressional.

\section{INTRODUCTION}

The processes occurring during continent-continent collision are still poorly understood. Ascertaining the seismic properties of the crust and uppermost mantle in such settings provides insight into continental rheology and geodynamics. The ongoing collision between India and Eurasia has resulted in the uplift of the Himalayas and Tibet, the highest mountain range $(\sim 8000 \mathrm{~m})$ and the largest $\left(\sim 2.5 \times 10^{6} \mathrm{~km}\right)$ and highest $(\sim 4500 \mathrm{~m})$ plateau on the Earth today. Because of its magnitude and that it is still active, the Himalayan-Tibetan orogen is the best natural laboratory for investigating continent-continent collisional processes. By understanding the processes that are occurring today in the Himalayas and Tibet, insight might also be gained about processes that may have occurred in past, possibly similar settings, for example, during the $\sim 1$ Ga old Grenville Orogeny in Laurentia.

Over the past $\sim 40 \mathrm{yr}$ the results of a growing number of passive and active seismic experiments (e.g. Kaila \& Krishna 1992; Zhu 
et al. 1995; Kind et al. 2002; Shapiro et al. 2004; Mitra et al. 2005; Acton et al. 2010; Zhang et al. 2011; Borah et al. 2014) have illuminated the crust and uppermost mantle structure of the Indo-Eurasian collision zone. These studies show that the crust of the Indian Shield south of the Ganga Basin is $30-40 \mathrm{~km}$ thick and relatively simple and uniform. Beneath the Himalayas the crust thickens to $50-60 \mathrm{~km}$ and has a complex internal structure. To the north of the Himalayas, in southern Tibet, the Mohorovičić discontinuity (Moho) deepens to as much as $90 \mathrm{~km}$ with a low wave speed upper and middle crust, and a higher wave speed lower crust. Farther north, crustal wave speeds remain low but the Moho shallows to $50-60 \mathrm{~km}$ at the northern edge of the Plateau.

It is almost 100 years since it was first suggested that the Himalayas and Tibet result from the collision with, and subsequent underthrusting of, India beneath southern Eurasia (Argand 1924). While this continent-continent collision is now the accepted cause for the uplift of the Himalayan Mountains and the Tibetan Plateau, the details of how this occurs and the state of the lithosphere beneath southern Asia, and in particular the Tibetan Plateau, are still contested. One fundamental question is how far north Indian lithosphere extends beneath the Plateau. It is accepted that underthrusted Indian continental lithosphere is responsible for the high wave speeds underlying the Himalayas and the southern part of the Plateau (Zhao et al. 1993; Mitra et al. 2005; Nábělek et al. 2009; Acton et al. 2011). Low seismic shear wave speeds $\left(V_{\mathrm{s}}\right)$ (e.g. Zhao et al. 1993; McNamara et al. 1997; Ritzwoller et al. 2002; Shapiro \& Ritzwoller 2002) and attenuation of shear waves (Ni \& Barazangi 1983; Barron \& Priestley 2009) in northeast Tibet imply that the upper mantle there is relatively warm. Some (e.g. Houseman et al. 1981; Molnar et al. 1993) suggest that these observations show that Indian lithosphere has delaminated beneath northeast Tibet. Others (e.g. Griot et al. 1998; Priestley \& McKenzie 2006, 2013) suggest that there is thick $(\sim 250 \mathrm{~km})$ lithosphere beneath most, if not all, of Tibet and that the low wave speed is due to radioactive heating of the thickened Tibetan crust (McKenzie \& Priestley 2008, 2016). Various geological (e.g. Searle et al. 2011) and geophysical (e.g. Brown et al. 1996; Makovsky et al. 1996; Nelson et al. 1996; Wei et al. 2001) observations have been cited as evidence for a warm, weak Tibetan mid-crust.

There are now a large number of studies of the Tibetan crust, and some discussing Himalayan crustal structure but most have focused on limited areas. The crustal structure of the Ganga Basin and Indian Shield south of the Himalayas is slowly becoming better known but suffers because of a lack of publicly available seismic data. To fully understand how Tibet is evolving and to discriminate between different proposed deformation models, seismic images of the entire Indo-Eurasian collision zone are required. In this study, we provide new, high-resolution fundamental mode Rayleigh wave group velocity maps for Indo-Eurasian collision zone.

In this paper, we focus on the seismic structure of the crust and uppermost mantle of the Indo-Eurasian collision zone. In Section 2, we discuss the data and analysis we carry out to investigate the shear wave structure of the Indo-Eurasian collision zone. By analysing regional earthquake seismograms and ambient noise from data recorded on recently deployed broad-band seismic instruments in this region we are able to improve significantly on the resolution of surface wave observations of the entire Indo-Eurasian collision zone. In Section 3, we show how Rayleigh wave group velocity varies across the region. In Section 4, we discuss how the Rayleigh wave group velocity data are used to interpret the crust and uppermost mantle structure of the Indo-Eurasian collision zone. We use these surface wave dispersion results to obtain maps of shear velocity structure for the crust and uppermost mantle throughout the region. These new images provide insight into the evolution of the Indo-Eurasian collision zone and allow us to address a fundamental question concerning the Himalayan-Tibetan orogen, namely, the variation in the internal structure and thickness of the crust across the Indo-Eurasian collision zone. In Section 5, we discuss possible causes of the mid-crustal low velocity layer.

\section{DATA AND ANALYSIS}

Data used to construct the fundamental mode Rayleigh wave group velocity maps come from permanent and temporary broad-band seismic stations deployed throughout central and southern Asia (Fig. 1). In addition to new dispersion measurements made for this study, we include the dispersion measurements made by Acton et al. (2010), Nunn et al. (2014a), Gilligan et al. (2014) and Gilligan et al. (2015) which were all made in an identical manner. From the stations shown in Fig. 1, seismograms from earthquakes $M>4.5$ with adequate signal-to-noise and within $3000 \mathrm{~km}$ of the site were analysed to obtain path-average fundamental mode Rayleigh wave group velocity dispersion. To increase the number of short-period measurements and improve path density, we determined intrastation Green's functions from ambient noise cross-correlations. We used 767 stations from permanent and temporary networks in China, Kyrgyzstan, Tajikistan, India and Nepal. Not all of these networks were operational at the same time.

Group velocity dispersion curves for fundamental mode Rayleigh waves from earthquakes were obtained using Frequency Time Analysis (Dziewonski et al. 1969; Levshin et al. 1972) with phasematched filtering. For the ambient-noise analysis we follow the procedure outlined in Bensen et al. (2007) to obtain the crosscorrelations. We reject station pairs where the signal-to-noise ratio of the stacked cross-correlations is less than 15, leaving a total of 5698 stacked cross-correlations. We also include unpublished ambient noise measurements from the NGRI (National Geophysical Research Institute) Uttaranchal network and from published ambient noise measurements on the south Indian Shield (Borah et al. 2014). The dispersion from the earthquake seismograms was determined manually; the dispersion from the ambient noise Green's functions was determined automatically (Levshin \& Ritzwoller 2001).

Fundamental mode Rayleigh wave group velocity dispersion curves were obtained for periods from 5 to $70 \mathrm{~s}$ for a total of 20816 paths, although the number of paths at individual periods is smaller (Supporting Information Fig. SA1). Of these, 4424 are new dispersion curves from this study for earthquake data and 5698 are new measurements from ambient noise data. The remaining dispersion curves come from previously published studies (Acton et al. 2010; Nunn et al. 2014a; Gilligan et al. 2014, 2015). There is considerable redundancy in the dispersion data set and we use this redundancy to identify and remove outliers, and to estimate errors in the dispersion data.

To construct fundamental mode Rayleigh wave group velocity tomographic maps, a region including all sources and receivers is parametrized by a 2-D mesh consisting of nodes of triangular elements on a spherical surface. Throughout most of the region the node spacing is $1^{\circ}$, but in regions with high path density and shorter periods - primarily the regions constrained with ambient noise data - we embed a finer grid with node spacing of $0.25^{\circ}$ for the 5 and $8 \mathrm{~s}$ tomographic inversions, and $0.5^{\circ}$ for the 10,12 , 15 and $18 \mathrm{~s}$ tomographic inversions. There is a gradual transition 


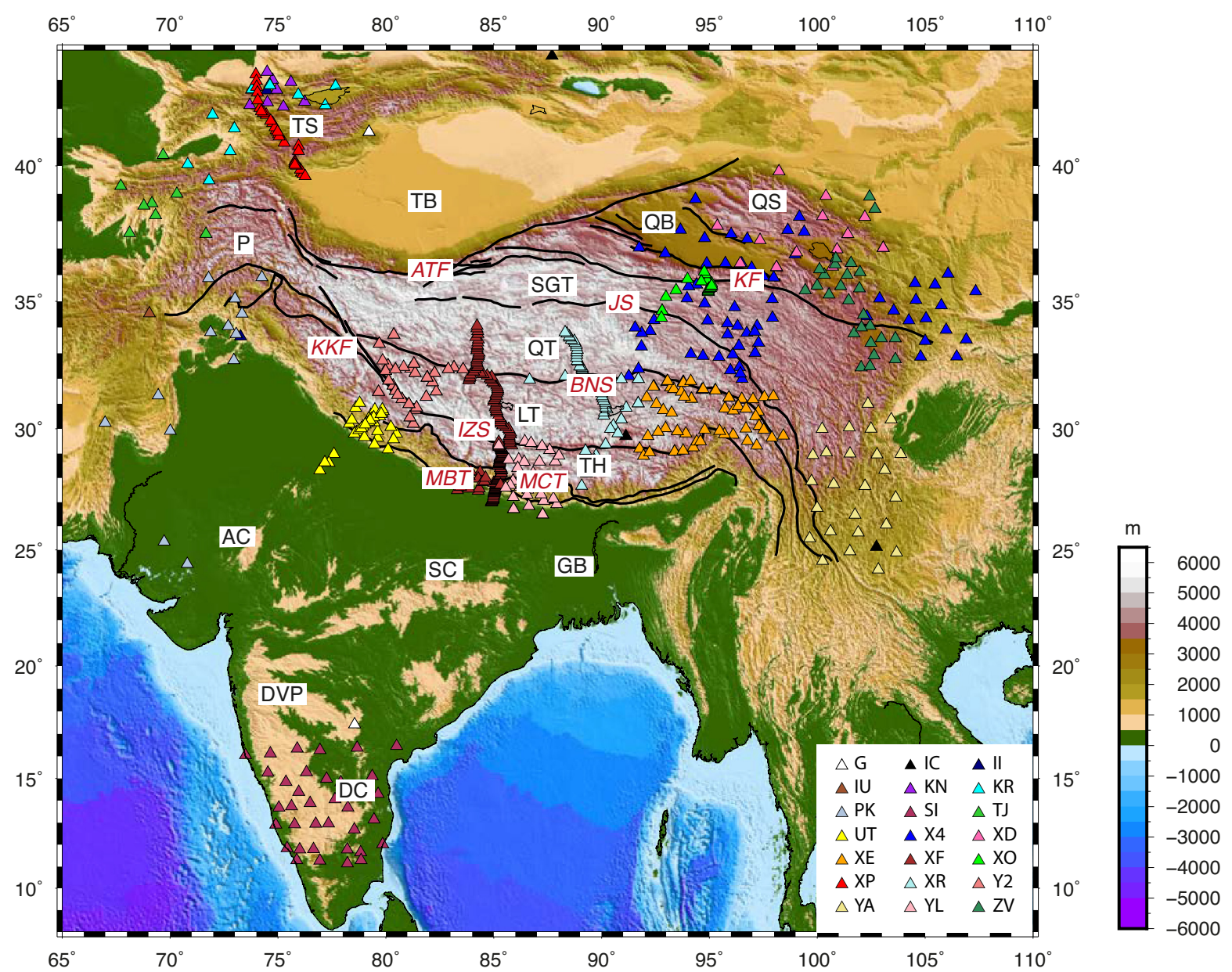

Figure 1. Topography map of the Indo-Eurasian collision zone indicating the location of the main geologic terrane, faults and seismic stations used in determining the fundamental mode group velocity dispersion. IYS, Indus-Yalong Suture; BNS, Bangong-Nujiang Suture; JS, Jinsha River Suture; TH, Tethyan Himalaya; LB, Lhasa Block; QT, Qiangtang Terrane; SGT, Songpan-Ganze Terrane; QB, Qaidam Basin; TB, Tariam Basin; GB, Ganga Basin; DVP, Deccan Volcanic Province; DC, Dharwar Craton; SC Singbhum Craton; AC, Aravalli Craton; KUF Kunlun Fault; KAF, Karakorum Fault; ATF, AltynTagh Fault; MBT, Main Boundary Thrust; MCT, Main Central Thrust; MHT, Main Himalayan Thrust. Triangles indicate the locations of the seismic stations used and are coloured by network. With the exception of PK, Pakistan Metrological Department; SI, NGRI Southern India and UT, Uttaranchal, all other network codes are those given by IRIS DMC.

from the coarser $1^{\circ}$ grid to the finer grid to avoid edge effects. Tomographic inversions were performed at 14 periods between 5 and $70 \mathrm{~s}$. Using the path-averaged Rayleigh wave group velocity dispersion measurements, the group slowness for a given period at each node is calculated as described by the straight-ray approach of Mitra et al. (2006). Wave speeds within each triangular element are calculated using a three-point linear interpolation. Resolution is not constant over the whole of the Indo-Eurasian collision zone. Resolution tests (Supporting Information Fig. SA5) demonstrate that for $10-50 \mathrm{~s}$ periods features as small as $3^{\circ}$ are well resolved throughout the region; for $60 \mathrm{~s}$ and $70 \mathrm{~s}$ periods the resolution is $\sim 5^{\circ}$. For periods of 5-30 s features as small as $2^{\circ}$ are resolved in Southern India and Tibet, and at $8 \mathrm{~s}$ it is also possible to resolve features as small as $1^{\circ}$ in southern India and some parts of Tibet.

\section{VARIATION IN FUNDAMENTAL MODE RAYLEIGH WAVE GROUP VELOCITY ACROSS THE INDO-EURASIAN COLLISION ZONE}

We obtain Rayleigh wave group velocity maps at 14 periods between 5 and 70 s. Fig. 2 shows tomographic group velocity maps for several representative periods. The short-period group velocities are sensitive to upper crustal structure and the short-period maps show areas of low velocity in regions of thick sediments (Laske et al. 1997). One indication of the resolution we attain at these periods is indicated by our short-period dispersion maps resolving the two separate depositional centres in the Tarim Basin which are separated by the Bachu uplift (Desheng et al. 1996). The Qiadam, Katawaz, Ganga and Afghan-Tajik Basins and the Indo-Burman fold belt all show low group wave speeds at short periods. The low group velocities associated with sediment fill in the Himalayan foreland basin are at their widest extent in north-central India and become narrower westwards till they merge with the region of low group velocities associated with the Katawaz Basin — the sediments of the palaeodelta of the Indus River. 

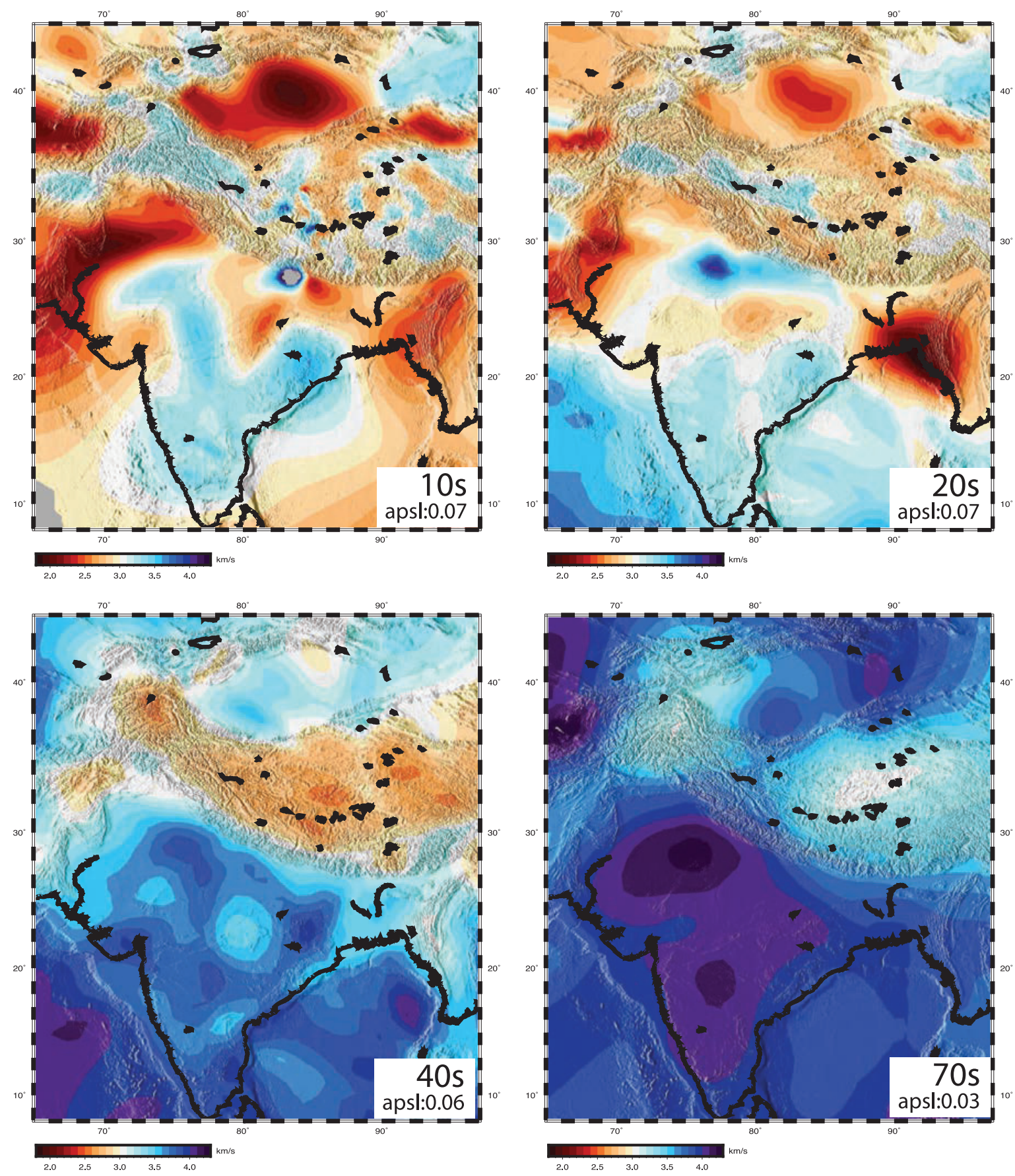

Figure 2. Fundamental mode Rayleigh wave group velocity maps for 5-70 s. The period and corresponding apsl (a priori constraint on the standard deviation of the slowness across a reference distance on the grid, see Supporting Information Appendix SA6) value are marked on the maps. Areas with errors greater than $0.5 \mathrm{~km} \mathrm{~s}^{-1}$ are shaded grey. The same scale is used in all maps.

Low velocities associated with the Bengal Basin and the Bengal Fan extend to periods as long as $25 \mathrm{~s}$, reflecting the particularly large sediment thickness in that area-reported to be greater than $20 \mathrm{~km}$ in thickness (Alam et al. 2003). The pattern of low group velocities in the Bengal Basin and the Fan indicate that the sediment thickness of the Fan must progressively thin southwards, a feature also observed by Mitra et al. (2011). The low group velocities in northeastern India persist to $30 \mathrm{~s}$ period in the region of the eastern Himalayan syntaxis and the Naga Fold and Thrust Belt reflecting the thick sediments and deeper Moho beneath the Naga Fold and Thrust Belt.
Cratonic areas in India show high group velocities at longer ( $>40 \mathrm{~s}$ ) periods. The Indian Shield has the high group velocities reaching $3.8 \mathrm{~km} \mathrm{~s}^{-1}$ at $40 \mathrm{~s}$ period, and up to $4.2 \mathrm{~km} \mathrm{~s}^{-1}$ at $70 \mathrm{~s}$ period. The three cratonic cores of the Indian Shield - the Singbhum, Aravalli and Dharwar cratons-are also distinguishable as three separate regions of high velocity at short periods, partially due to thin sedimentary cover. Short-period group velocities for Tibet are slower than that for the Indian Shield, but higher than found in areas of thick sediment accumulation. The pattern of fast and slow anomalies for Tibet is on a shorter length scale $\left(3^{\circ}-5^{\circ}\right)$ than elsewhere, reflecting the heterogeneity of the upper crust. Group 
velocities that are lower than most of the rest of the region persist to long periods reflecting the thickened Tibetan crust. At $70 \mathrm{~s}$ there are still group velocities as low as $3 \mathrm{~km} \mathrm{~s}^{-1}$ in northeastern Tibet. At 60 and $70 \mathrm{~s}$ group velocities are faster beneath west Tibet than east Tibet.

Our tomographic inversion method does not invert for azimuthal anisotropy, however it is likely that the Tibetan crust is strongly anisotropic. A recent study by Agius \& Lebedev (2017), for example, finds that there is between $3 \%$ and $8 \%$ azimuthal anisotropy in the mid-crust beneath the Plateau. While the anisotropic component of velocity may trade-off with the heterogeneity in group velocity, synthetic tests (e.g. Pilidou et al. 2004; Debayle \& Ricard 2013) demonstrate that this effect is likely to be small $(\sim 2 \%)$ compared to the heterogeneity we observe in our group velocity maps. Further, vorinoi diagrams (Supporting Information Fig. SA3) show that our azimuthal data coverage is sufficient over the Indo-Eurasian collision zone to average out the azimuthal anisotropy.

\section{SHEAR WAVE SPEED STRUCTURE OF THE INDO-EURASIAN COLLISION ZONE}

\subsection{Determining the crust and uppermost mantle structure}

Fundamental mode Rayleigh wave group velocity dispersion curves were extracted from the group velocity maps at $1^{\circ}$ intervals for the Indo-Eurasian collision zone. The dispersion curves were then inverted for crust and uppermost mantle shear velocity using surf 96 (Herrmann 2004). The starting model is parametrized by $2 \mathrm{~km}$ thick layers of $V_{\mathrm{s}}=4.48 \mathrm{~km} \mathrm{~s}^{-1}$ (the upper-mantle velocity of ak135; Kennett et al. 1995) and $V_{\mathrm{p}} / V_{\mathrm{s}}=1.79$ to a depth of $100 \mathrm{~km}$ and overlying the ak135 mantle. Since there is no a priori crustal information in the inversion starting model, the crustal structure in the inversion models is completely dictated by the data. Fundamental mode Rayleigh wave sensitivity kernels show (Supporting Information Fig. SA2), and forward modelling confirms (Supporting Information Fig. SA4), that the dispersion data have negligible sensitivity to shear wave structure below about $120 \mathrm{~km}$, hence we do not interpret features below that depth. The 1-D models from the surface wave dispersion inversions were then combined to produce a 3-D shear wave model for the crust and uppermost mantle for the whole of the Indo-Eurasian collision zone.

Short-period surface waves are sensitive to the crustal wave speeds and to the depth of the Moho but, because of the wavelengths involved, they are not sensitive to sharp velocity changes like the Moho. Consequently, inversion of surface wave dispersion data produces a smoothed model of the structure. To better constrain the crustal structure, we have computed P-receiver functions at a number of sites. Seismograms from teleseismic earthquakes, $5.5>$ $M>6.9$, at distances $25^{\circ}$ to $90^{\circ}$ from the stations were used to calculate radial P-receiver functions using the method of Ligorría \& Ammon (1999).

Neither short-period surface waves nor receiver functions on their own provide unique constrains on crustal structure. Short-period surface waves constrain the absolute velocity of the crust but provide weak constraints on discontinuities. On the other hand, receiver function analysis provides constrains on discontinuities but there is a trade-off between the depth to an interface and the wave speed above the interface. Therefore, we jointly invert the receiver function and the surface wave dispersion data, providing a stronger constraint on the crustal model beneath selected sites.
We use the joint 96 code of Herrmann (2004) with the same starting model as we use in the inversion of the surface wave dispersion data. The starting model is parametrized by $2 \mathrm{~km}$ thick layers of $V_{\mathrm{s}}$ $=4.48 \mathrm{~km} \mathrm{~s}^{-1}$ and $V_{\mathrm{p}} / V_{\mathrm{s}}=1.79$ to a depth of $100 \mathrm{~km}$ and overlying an ak135 mantle, that is, there is no a priori Moho or other crustal structure in the inversion starting model. To further test the effect of the starting model on the inversion result, we preformed two further sets of inversions with the starting model parametrized in the same way as described above but with a $V_{\mathrm{s}}=4.28 \mathrm{~km} \mathrm{~s}^{-1}$ in one set of inversions and $V_{\mathrm{s}}=4.68 \mathrm{~km} \mathrm{~s}^{-1}$ in a second set of inversions. We use a weighting of receiver function to surface wave data of 80:20 for our final results but tested other weightings from 99:1 to 75:25. The main difference in the inversions when the weighting was varied was that the crust/upper-mantle model became smoother as the weight of the surface wave was increased. While the weighting between the two types of data is subjective, this relative weighting we choose ensures we maximize the receiver function data in the joint inversion, while still resulting in a good fit to the surface wave data. We define the Moho depth as the base of the steepest positive velocity gradient where $V_{\mathrm{s}}>4 \mathrm{~km} \mathrm{~s}^{-1}$, and use the crustal models obtained from the joint inversion (Fig. 5) as a guide to identifying the Moho in the inversions of just surface wave data.

\subsection{Lateral variations in crustal-mantle boundary}

At shallow depths ( $\sim 10 \mathrm{~km}$; Figs $3 \mathrm{a}$ and $4 \mathrm{a}$ and $\mathrm{b})$ shear velocities average $\sim 3.5 \mathrm{~km} \mathrm{~s}^{-1}$ beneath most of India but less than $\sim 3.4$ $\mathrm{km} \mathrm{s}^{-1}$ beneath most of Tibet. The shear velocities are lowest $(<3$ $\mathrm{km} \mathrm{s}^{-1}$ ) in sedimentary basins (e.g. Tarim, Qiadam, Bengal and Ganga Basins). At depths of $20-40 \mathrm{~km}$ (Figs $3 \mathrm{~b}$ and 4) there is a pervasive low velocity layer $\left(<3.4 \mathrm{~km} \mathrm{~s}^{-1}\right)$ throughout Tibet and the Pamir but not within the crust of the Indian Shield. The depth to the Moho varies greatly over the Indo-Eurasian collision zone with a crustal thickness of 40-50 km in southern India, 30-40 km beneath the South Indian Shield, $50-60 \mathrm{~km}$ beneath the Himalayas and $65-90 \mathrm{~km}$ below Tibet.

The Moho beneath most of the India Shield, as seen in the surface wave models, is a relatively sharp transition at a depth of $30-40 \mathrm{~km}$ (Figs $4 \mathrm{a}$ and b). In the far south, the crust of the South Indian Shield is as thick as $40-50 \mathrm{~km}$. Our surface wave observations are consistent with the Moho depth observed in receiver functions (e.g. Gupta et al. 2003; Rai et al. 2003; Borah et al. 2014). Crustal shear wave models from the joint inversion of receiver function and surface wave data at six representative sites on the India Shield are shown in Fig. 5. The $44 \mathrm{~km}$ thick crust beneath KOD located on the Pan-Africa age Southern Granulites terrane in the far south has an average $V_{\mathrm{s}}$ of $3.88 \mathrm{~km} \mathrm{~s}^{-1}$. The crust beneath GDP located on the mid-Archaean west Dharwar craton is $44 \mathrm{~km}$ thick with an average $V_{\mathrm{s}}$ of $3.80 \mathrm{~km} \mathrm{~s}^{-1}$. The internal structure of the crust of both the Southern Granulite terrane beneath KOD and the west Dharwar craton beneath GDP is more complex than that of the late-Archaean east Dharwar craton, as shown by the crustal structure beneath the sites at GBA, HYB, WRD and ALB. Beneath the eastern Dharwar craton the Moho is at $32-38 \mathrm{~km}$ depth and the average crustal $V_{\mathrm{s}}$ is $3.65-3.70 \mathrm{~km} \mathrm{~s}^{-1}$. The crustal Airy phase of the fundamental mode group velocity is at $20 \pm 5 \mathrm{~s}$ for the east Dharwar craton.

Fig. 5 also shows two representative models for the Himalayas. The crust thickens beneath the Himalayas to $50-60 \mathrm{~km}$ and the crust-mantle transition is more gradational than beneath the South Indian Shield. The Moho beneath GTOK in the eastern Himalayas is at $54 \mathrm{~km}$ depth and the average $V_{\mathrm{s}}$ of the crust is $3.61 \mathrm{~km} \mathrm{~s}^{-1}$ while 

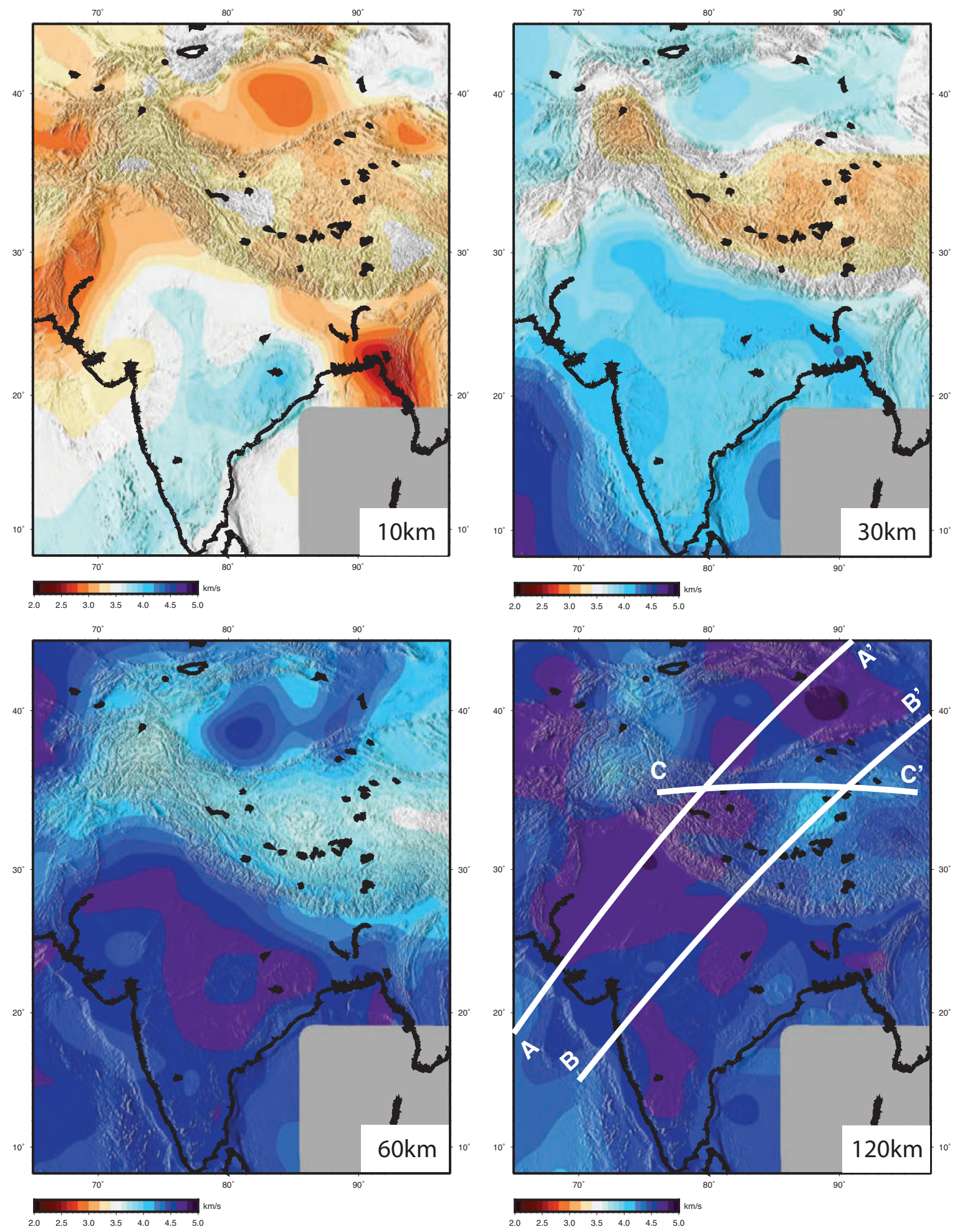

Figure 3. Contour maps of shear wave speed for depths $10-120 \mathrm{~km}$ resulting from the inversion of the group velocity dispersion curves on a $1^{\circ} \times 1^{\circ}$ grid across the whole of the Indo-Eurasian collision zone. The scale is the same for all figures.

the crust beneath ALM in the central Himalayas is $53 \mathrm{~km}$ thick and the average $V_{\mathrm{s}}$ of the crust is $3.67 \mathrm{~km} \mathrm{~s}^{-1}$.

Fig. 6 shows the group velocity dispersion curve, receiver function and crustal shear wave structure for 10 representative sites across the Tibetan Plateau. The Moho beneath Tibet is variable in depth and sharpness and the average crustal $V_{\mathrm{s}}$ is significantly slower (3.25-3.45 $\mathrm{km} \mathrm{s}^{-1}$ ) than beneath the Himalayas and southern India. As Chun \& Yoshii (1977) first observed, the fundamental mode Rayleigh wave crustal Airy phase has a minimum at $\sim 35 \mathrm{~s}$, a significantly longer period than that observed for most regions of the continents. 

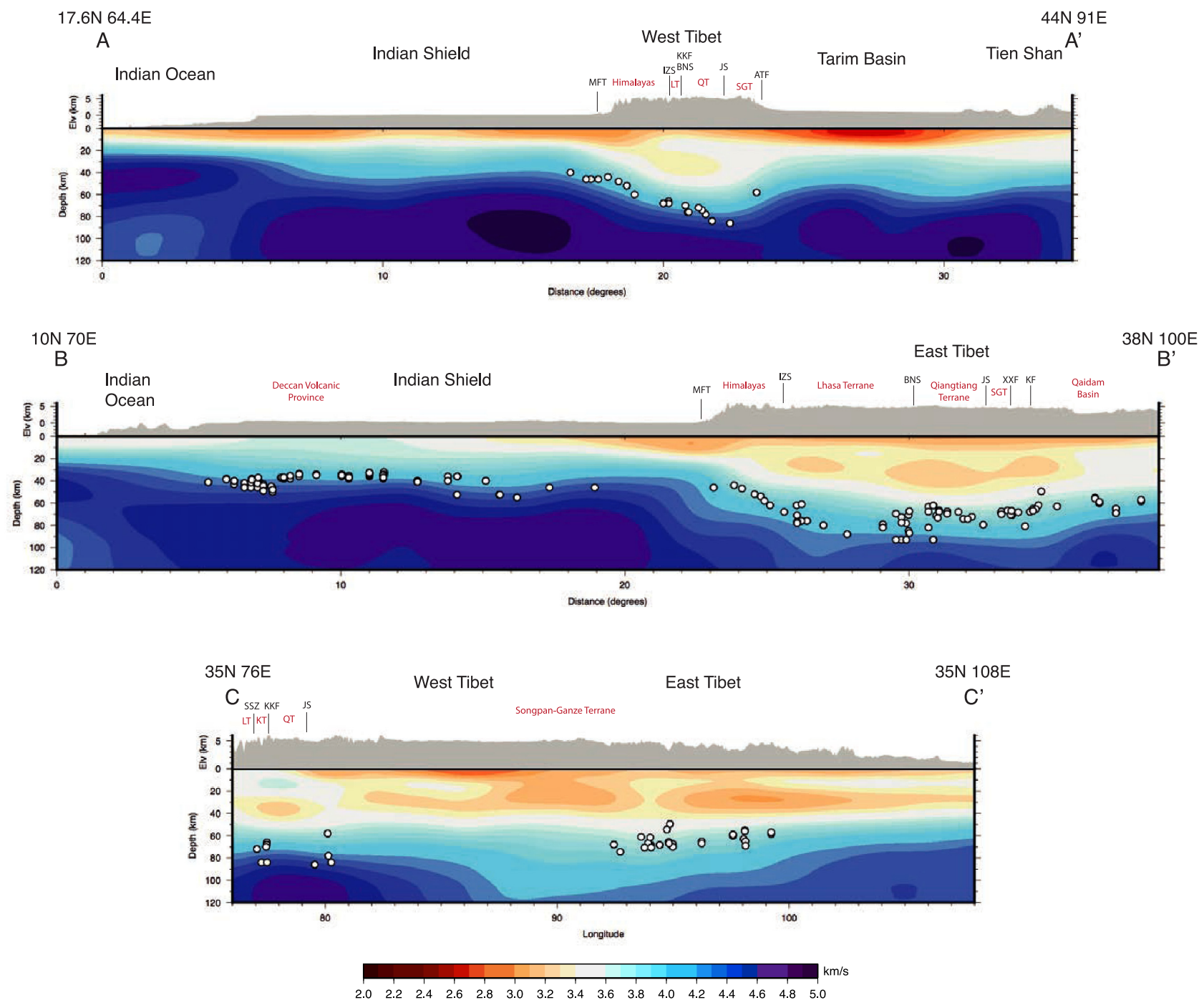

Figure 4. Shear velocity versus depth profiles obtained from the inversion of fundamental mode Rayleigh wave group velocity data. (a) Western India and west Tibet (A-A $17.6^{\circ} \mathrm{N}, 64.4^{\circ} \mathrm{E} 44^{\circ} \mathrm{N}, 91^{\circ} \mathrm{E}$ ), (b) central India and east Tibet (B-B $10^{\circ} \mathrm{N}, 70^{\circ} \mathrm{E} 36^{\circ} \mathrm{N}, 100^{\circ} \mathrm{E}$ ) and (c) W-E across the Tibetan Plateau at a latitude of $35^{\circ} \mathrm{N}\left(\mathrm{C}-\mathrm{C} 35^{\circ} \mathrm{N}, 76^{\circ} \mathrm{E} 35^{\circ} \mathrm{N}, 108^{\circ} \mathrm{E}\right)$. Profile topography is plotted above the section. White circles mark the depths of the Moho from joint surface wave dispersion - receiver function inversion in this study, additional unpublished Moho depth estimates determined in the same manner, and previously published Moho depth estimates from Gilligan et al. (2015), within $200 \mathrm{~km}$ of the line of section.

In western Tibet, the depth of the Moho defined from receiver function studies (Wittlinger et al. 2004; Rai et al. 2006; Zhang et al. 2014; Gilligan et al. 2015) agrees well with the depth of the steepest gradient in increasing shear velocity in our surface-wavederived model (Fig. 4). The velocity change at the Moho is from $\sim 3.8 \mathrm{~km} \mathrm{~s}^{-1}$ to $4.5 \mathrm{~km} \mathrm{~s}^{-1}$ similar to that beneath the Indian Shield (cross-section A-A', Fig. 4) suggesting that the Indian lithosphere underthrusts the western Plateau possibly as far as the Altyn Tagh Fault (e.g. Wittlinger et al. 2004; Rai et al. 2006; Gilligan et al. 2015). Beneath western (Fig. 6; WT17) and southern Tibet (Fig. 6; H1120 and ST01) the crust is as much as $90 \mathrm{~km}$ thick and the Moho is a relatively sharp wave speed transition. The crustal $V_{\mathrm{s}}$ in western and southern Tibet is $3.35-3.45 \mathrm{~km} \mathrm{~s}^{-1}$.

A similar correspondence between previously reported Moho depths and the steepest gradient of increasing shear velocity occurs in southeast Tibet, although the gradient is not as steep, and the uppermost mantle velocity is slightly lower $\sim 4.4 \mathrm{~km} \mathrm{~s}^{-1}$. This is consistent with the interpretation made in previous receiver function studies (e.g. Mitra et al. 2005; Nábělek et al. 2009) that Indian lithosphere is present at least as far north as the Bangong-Nujiang Suture. In north-central Tibet (Fig. 6; H1630 and ST40), the Moho transition has a similar character to that below western and southern Tibet but the crust is only $60-65 \mathrm{~km}$ thick and the crustal $V_{\mathrm{s}}$ is $3.25-$ $3.35 \mathrm{~km} \mathrm{~s}^{-1}$.

North of $32^{\circ}$ in eastern Tibet, the velocities at receiver function defined Moho depths (Fig. 6; C08 and D04) are significantly lower $\left(\sim 3.8 \mathrm{~km} \mathrm{~s}^{-1}\right)$ and the gradient of increasing shear velocity is very gradual (cross-section B-B', Fig. 4). The difference in Moho properties between northeastern and southeastern Tibet suggests that if Indian lithosphere is present, it must have either been heavily modified, be hot or have originally been of a very different composition to explain the low velocities.

\subsection{Lateral variations in the mid-crustal low velocity layer}

We examine the shear velocity models obtained from the inversion of surface waves at each $1^{\circ}$ point throughout India and Tibet between 

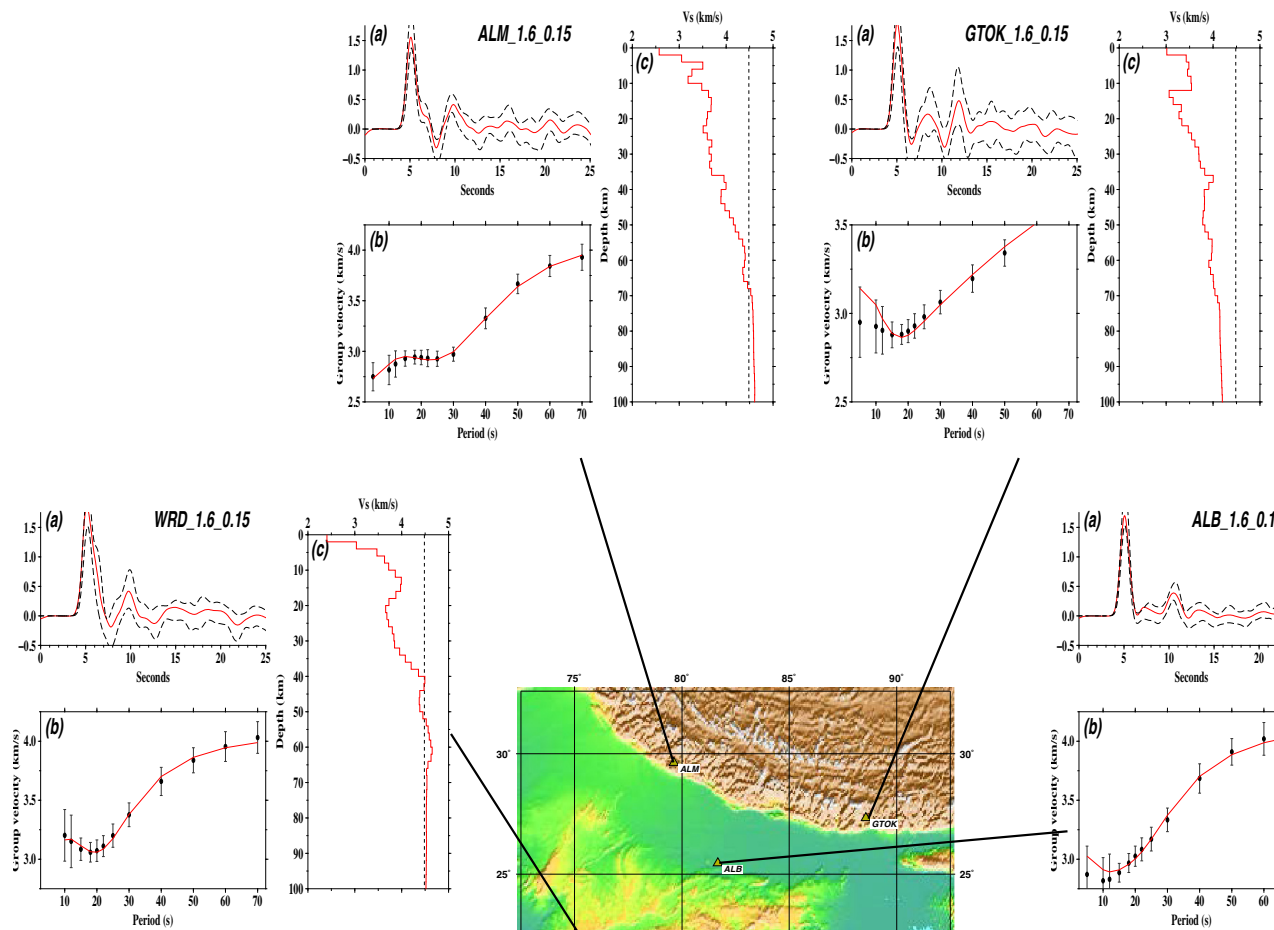

riod (s)
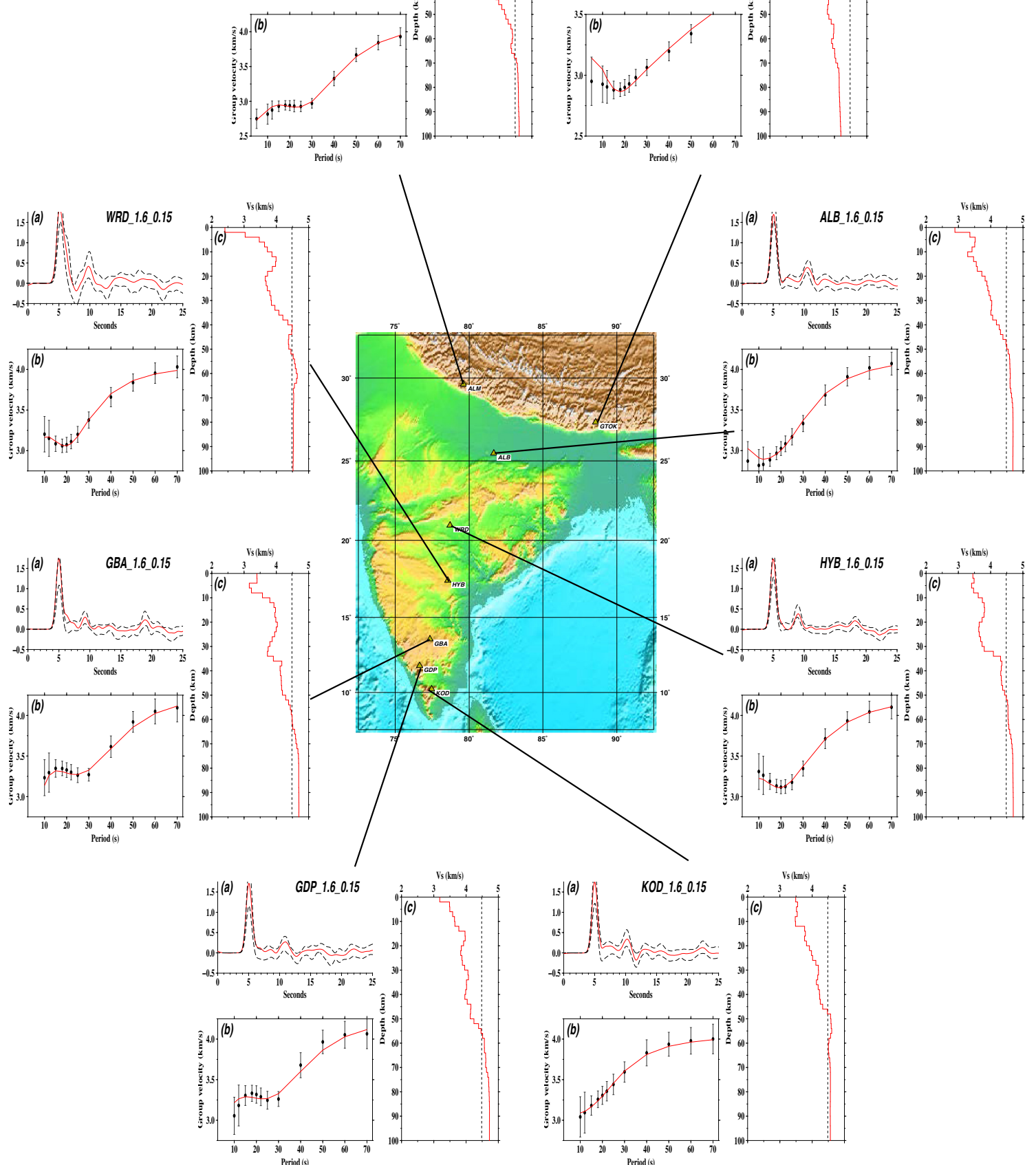

Figure 5. Results from the joint inversion of receiver functions and fundamental mode Rayleigh wave group velocity for representative sites on the South Indian Shield and the Himalayas. For each site (a) shows the $\pm 1 \sigma$ bounds for the observed receiver function (black dashed lines) and the synthetic receiver function for the final crustal structure (red solid line); (b) the observed dispersion (black circle with error bars) and the synthetic dispersion curve for the final velocity model (red solid line); and (c) the starting wave speed model for the inversion (black dashed line) and the final $V_{\mathrm{s}}$ model for the crust (solid red line).

10 and $50 \mathrm{~km}$ depth for the presence and character of a mid-crustal low velocity layer. We define the top of the low velocity layer as the depth at which velocities start to decrease, the middle as the depth when the velocities start to increase again, and the bottom as the depth when the velocities have returned to what they were at the top of the low velocity layer. The low velocity layer is confined to Tibet and the Pamirs, and the character of the low velocity layer, including properties such as the magnitude of the decrease and thickness of the layer, shows a spatial variation (Fig.7).

Within the crust of the Lhasa, Qiangtang, Songpan-Ghanze Terranes and beneath the Pamirs the minimum velocities are all less than $3.4 \mathrm{~km} \mathrm{~s}^{-1}$. The slowest velocities $\left(\sim 3 \mathrm{~km} \mathrm{~s}^{-1}\right)$ are found 


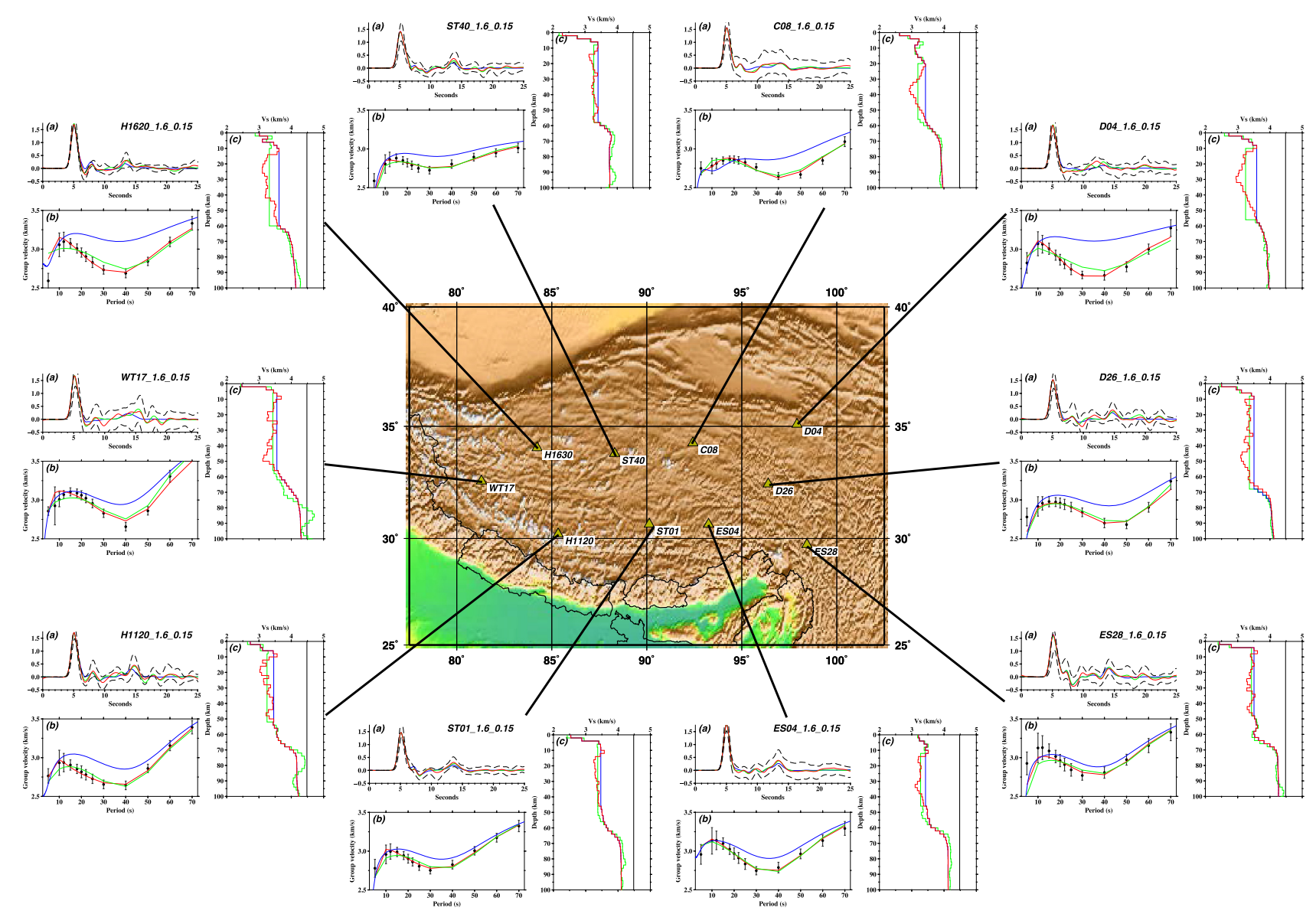

Figure 6. Results from the joint inversion of receiver functions and fundamental mode Rayleigh wave group velocity for representative sites on the Tibetan Plateau. Format of this figure is the same as that of Fig. 5 except that each panel has results for three crustal models- the model resulting from the joint receiver function - surface wave inversion (red solid lines), synthetic receiver function and dispersion curves for a simplified model without the low velocity layer (blue solid curves), and a joint receiver function — surface wave inversion using the blue velocity structure as the starting inversion model (green solid curves).

in central Tibet close to the Bangong-Nijang Suture, and in the Songpan-Ghanze Terrane in eastern Tibet (Fig. 7). The percentage decrease in velocity $\left(V_{\text {start }}-V_{\min } / V_{\text {start }}\right)$ shows a different spatial pattern to the absolute velocities: the largest decrease in velocities $(>8 \%)$ are found in the Songpan-Ghanze Terrane in east Tibet, within the Qiangtang Terrane in central Tibet and beneath the Pamir Mountains. There is a positive correlation between the decrease in velocity and the thickness of the low velocity layer.

We find no correlation between the variation in the properties of the low velocity layer and elevation. We also find no correlation between crustal thickness estimates and the properties of the low velocity layer. Although there are significant differences in the velocities of the uppermost mantle across Tibet, which exceed 4.5 $\mathrm{km} \mathrm{s}^{-1}$ in west Tibet but are much slower in northeast Tibet, we find no correlation between the velocities at $100 \mathrm{~km}$ depth with the properties of the low velocity layer.

There is no such low velocity layer in the Indian crust. Beneath most of India $V_{\mathrm{s}}$ is significantly faster- $3.8-4.0 \mathrm{~km} \mathrm{~s}^{-1}$ in the lower crust (25-40 km depth) and $>4.4 \mathrm{~km} \mathrm{~s}^{-1}$ below the Moho and exceeding $4.6 \mathrm{~km} \mathrm{~s}^{-1}$ at $70 \mathrm{~km}$ depth.

\subsection{Lateral variations in uppermost mantle shear wave speed}

At depths exceeding $80 \mathrm{~km}$, west Tibet is faster $\left(4.3-4.6 \mathrm{~km} \mathrm{~s}^{-1}\right)$ than east Tibet $\left(3.8-4.1 \mathrm{~km} \mathrm{~s}^{-1}\right)$ and at $110 \mathrm{~km}$ depth, the region west of $84^{\circ} \mathrm{E}$ has a similar velocity $\left(4.6 \mathrm{~km} \mathrm{~s}^{-1}\right)$ to the region below India and the Tarim Basin. In the southeast of Tibet, velocities are $>4.4$ $\mathrm{km} \mathrm{s}^{-1}$ for $\sim 300 \mathrm{~km}$ north of the Himalayas but slower immediately north of this. The slowest velocities are centred around $35^{\circ} \mathrm{N}, 89^{\circ} \mathrm{E}$.

The fast shear velocities observed in the uppermost mantle of west Tibet agree with previous seismic studies (e.g. Brandon \& Romanowicz 1986; Molnar 1990; Dricker \& Roecker 2002) that suggest that the upper mantle of west Tibet is faster than that of east Tibet. We have an improved resolution over a wider area than previous studies and can confirm that fast material is present across the entire width of the Plateau in western Tibet. Given the interpretation (Gilligan et al. 2015) that Indian crust is present beneath the entirety of west Tibet, it is likely that the fast uppermost mantle material that we observe extending across the entire western part of the Plateau is Indian mantle lithosphere. Furthermore, the uppermost mantle shear velocities we observe beneath western Tibet are similar $\left(\sim 4.5-4.6 \mathrm{~km} \mathrm{~s}^{-1}\right)$ to those beneath areas of the Indian Shield, providing further evidence that cratonic Indian material is likely to be present beneath west Tibet. This interpretation agrees with that made by Priestley et al. $(2006,2008)$ and Agius \& Lebedev (2013) 

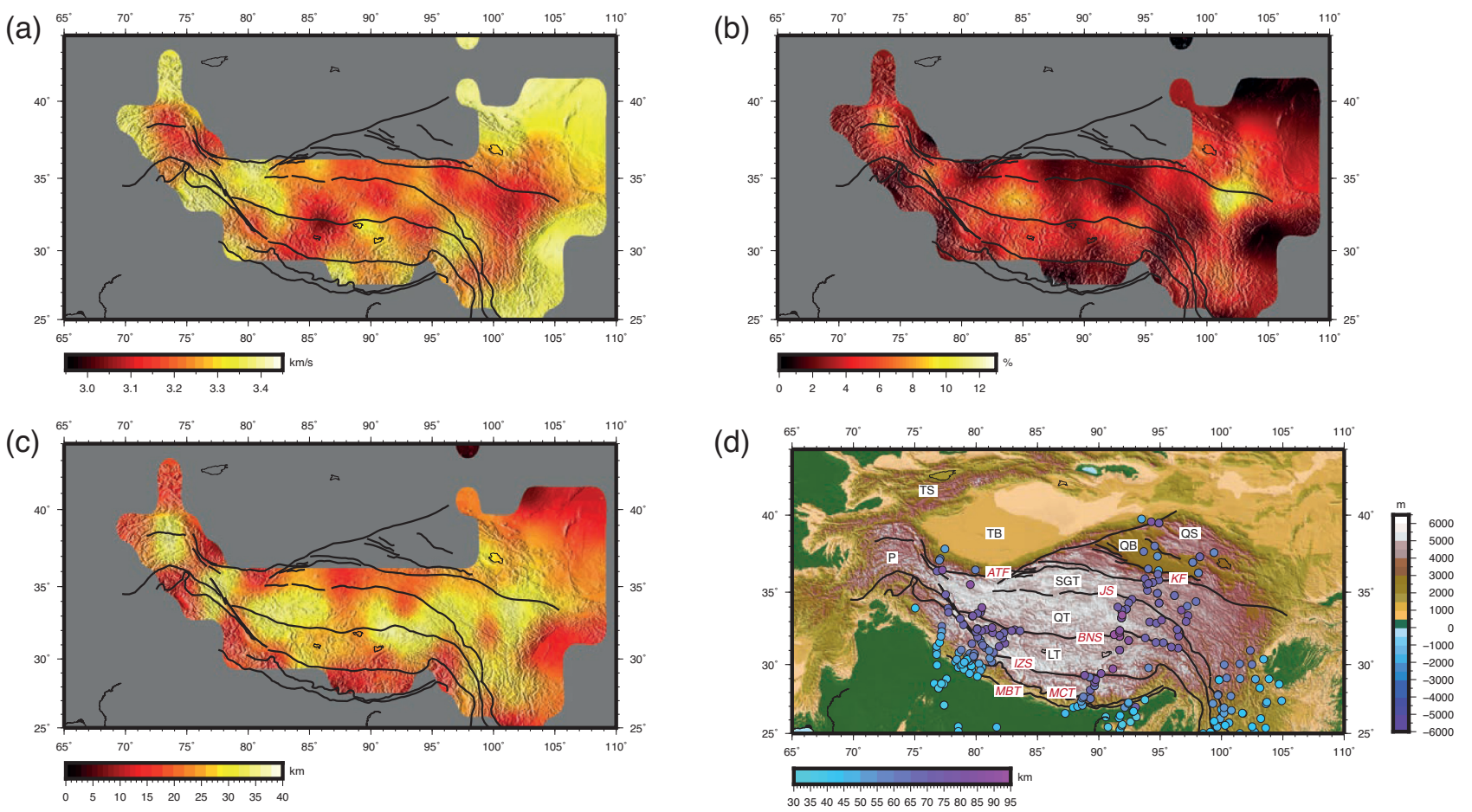

Figure 7. (a) The lateral variation in the minimum shear wave speed in the crustal low velocity layer. (b) The lateral variation in the shear wave speed decrease in the crustal low velocity layer defined as the drop in shear wave speed between the wave speed at the point where the decrease in shear wave speed begins and the minimum wave speed in the low velocity layer. (c) Thickness of the crustal low velocity layer defined as the vertical distance from the depth at which velocities start to decrease to the depth at which the velocities have returned to what they were at the top of the low layer. (d) The elevation and Moho depth in Tibet. Moho depths are compiled from estimates in this study, further unpublished results determined in the same way as this study, and Gilligan et al. (2015). The grey areas in (a)-(c) indicate areas in which no mid-crustal low velocity layer was observed in the shear velocity models obtained from the inversion of surface wave data.

from shear velocity models derived from long-period surface wave measurements.

Uppermost mantle velocities beneath the central and eastern Himalayas and southern part of the Lhasa Terrane are relatively fast $\left(\sim 4.4-4.5 \mathrm{~km} \mathrm{~s}^{-1}\right)$, although not as fast as those observed beneath west Tibet. North of $30^{\circ}-31^{\circ}$ uppermost mantle velocities are much lower: in some areas velocities exceeding $4 \mathrm{~km} \mathrm{~s}^{-1}$ are only reached at a depth of $120 \mathrm{~km}$. These observations may imply either that Indian lithospheric mantle material is only present beneath eastern Tibet south of the BNG or that it has been heavily modified since collision in the north. McKenzie \& Priestley (2008) suggest that radioactive heating could have warmed up the uppermost mantle lithosphere below thickened Tibetan crust. The very low velocities we observe in the uppermost mantle would require an unfeasibly long time period (greater than the time since the collision between India and Eurasia) for velocities as low as we observe to be present. While radiogenic heating may play a role in the low velocities we observe, it may be that Indian lithosphere beneath the northeast part of the Plateau has partially delaminated.

\section{POSSIBLE CAUSE OF THE LOW VELOCITY LAYER}

The low velocity layer we image (Fig. 7) throughout the mid-crust in most of Tibet has also been observed in a number of previous studies (e.g. Cotte et al. 1999; Rapine et al. 2003; Caldwell et al. 2009; Guo et al. 2009; Li et al. 2009; Yang et al. 2012; Agius \& Lebedev 2014; Jiang et al. 2014; Li et al. 2014; Sun et al. 2014; Bao et al. 2015; Deng et al. 2015; Gilligan et al. 2015). Our results have high resolution across the entire Tibetan Plateau and the Pamirs, whereas many previous studies have mainly focused on more restricted geographical regions. In particular, we have very good resolution in west Tibet, an area that has been less well resolved in previous studies (e.g. Yang et al. 2012). This means we are better able to examine the variations in the properties of the low velocity layer (e.g. depth, thickness, velocity decrease) across the entire region and thus potentially help to constrain what is leading to the decrease in velocity seen across the Plateau.

Various explanations have been put forward as to the cause of the mid-crustal low velocity zone including the presence of partial melt (Caldwell et al. 2009; Hacker et al. 2014; Jiang et al. 2014), aqueous fluids (Caldwell et al. 2009), anisotropy from the alignment of micas in the crust (Yang et al. 2012; Hacker et al. 2014) or some combination of these mechanisms (Agius \& Lebedev 2014). These explanations imply that the mid-crust is mechanically weak (Klemperer 2006), providing support for the idea that deformation in Tibet occurs due to crustal flow (e.g. Jamieson et al. 2004). Yang et al. (2012) examine the differences in the velocity decrease across the Plateau, however their results have some notable differences to ours. While they see the largest decreases in velocity the regions around the edge of the Plateau, this is not the case in our study. In part this is likely because they define their percentage decrease based on the velocity at $30 \mathrm{~km}$ and the maximum velocity at 0 $20 \mathrm{~km}$. These depths do not necessarily correspond to the depths of the minimum and maximum velocities in the low velocity layer, and so they may be minimizing the anomaly in some locations. Even when we use their approach, we do not obtain the same distribution of velocity decreases. Although they also have generally 
good coverage throughout Tibet, the resolution in our models is superior in the west of Tibet. Broadly, our result show some agreement with the results of Agius \& Lebedev (2014), who also observe low shear velocities in the mid crust everywhere they sample in Plateau. They observe the lowest velocities in the Tibetan mid-crust in central-west Tibet and in northeast Tibet, the regions we also find the lowest velocities. Further, the lowest velocities they report in these regions are similar to those we obtain. There is some difference between their results and ours in central Tibet, where the lowest velocity anomalies they observe are higher than those we observe in this region. Agius \& Lebedev (2014) combine the results obtained from path-average phase velocity curves for nine individual regions in Tibet. While they observe consistency within these regions, our results suggest that there may be more intraregion variability than they show, which could account for some of the differences between our results, particularly in central Tibet.

Partial melt and/or the presence of aqueous fluids in the midcrust have been the favoured explanation of the low velocity zone observed in many previous studies (e.g. Caldwell et al. 2009; Hacker et al. 2014; Jiang et al. 2014). Velocities less than $3.4 \mathrm{~km} \mathrm{~s}^{-1}$, such as those observed throughout the Tibetan Plateau would be in agreement with the presence of melt from rocks of composition and temperatures that are plausible for Tibet (Hacker et al. 2014). Further, this explanation also agrees with magnetotelluric studies in southeast Tibet (Unsworth et al. 2004) and in the Pamirs (Sass et al. 2014) that observe a conductive layer in the mid-crust, which would be consistent with the presence of melt and/or fluids. A key problem with the idea of melt being the main cause of the low velocities observed across the Plateau is the lack of recent volcanism (e.g. Chung et al. 2005) across the Tibetan Plateau. Hacker et al. (2014) suggest that this could be explained by either earlier melting events already depleting the crust, meaning that only small amounts of melt are produced by present heating, or by the melts that are produced not reaching the surface because they are highly viscous or are produced in small batches that freeze without erupting.

Temperatures in the middle of the Tibetan crust are thought to be around $800-1100{ }^{\circ} \mathrm{C}$, (Hacker et al. 2000, 2014). Agius \& Lebedev (2014) argue that temperatures of $\sim 800{ }^{\circ} \mathrm{C}$ are sufficient to account for the low shear velocities they observe in central Tibet. Although the exact composition and fluid content in the mid to lower crust of Tibet are poorly known, dry rocks would be expected to start to melt at $900{ }^{\circ} \mathrm{C}$ (Litvinovsky et al. 2000; Hacker et al. 2014), while the presence of water would lower the solidus temperature. Elevated temperatures have been explained through heating of the crust by asthenospheric material after the delamination or thinning of the lithosphere beneath Tibet (e.g. Owens \& Zandt 1997; Chung et al. 2005). The challenge for this model, in the context of our results, is that in west Tibet there appears to be fast, presumably cold, lithospheric material across the whole of the Plateau, yet some of the largest decreases in velocity are found in this region. Chung et al. (2005) suggest that underthrusting of Indian lithospheric material in southern Tibet may be why there is no lithospheric induced magmatism younger than $\sim 13-10 \mathrm{Ma}$ in this part of the Plateau.

An alternative source of heat could be from radioactivity in thickened crust (Jamieson et al. 1998; McKenzie \& Priestley 2008). Indeed, the low velocities could simply be due to elevated temperatures (Christensen 1979) as such heating could be expected to result in a shear velocity decrease of the magnitude we observe. This model does not require melt to be present, although does not preclude it. The degree of heating will depend on the amount of thickening and the length of time the crust has been thick, however temporal evolution of the Tibetan Plateau is, at present, poorly constrained. Better understanding of when, as well as how, the crust in Tibet thickened would help to place limits on the how much of a velocity decrease could be expected from radiogenic heating.

Another proposal is that the magnitude of velocity decrease observed could largely be achieved due to radial anisotropy in the mid-crust (Shapiro et al. 2004; Yang et al. 2012; Xie et al. 2017). Anisotropy would likely arise due to the alignment of metamorphic minerals such as mica and amphibole that are present in the mid-crust. Variability in the degree of anisotropy may be a function of strain and whether anisotropic minerals are present in the first place (Yang et al. 2012). Estimates of radial anisotropy from Love and Rayleigh waves by Shapiro et al. (2004) suggest that the anisotropy is greatest in central-west Tibet in the Qiangtang terrane and southeast-south-central Tibet. The region of strong anisotropy in the Qiangtang Terrane coincides with one of the areas in which we observe the largest decrease in shear velocity, indicating that anisotropy is likely to be responsible for at least some of the velocity decrease observed in this regions. Although Shapiro et al. (2004) and Agius \& Lebedev (2014) favour crustal thinning as the mechanism for aligning micas based on earthquake observations, they do also suggest that underthrusting of the Indian crust beneath Tibet will result in strong shearing and align mica crystals. The fast uppermost mantle velocities we find in western Tibet suggest that Indian material is likely present across the whole plateau, and thus underthrusting may have contributed to alignment of mica in this region.

To test this further we use the Love wave group velocity tomography of Acton et al. (2010) to investigate the difference between horizontal and vertically polarized shear velocities. This tomography is performed in the same way as the Rayleigh wave tomography we present here, although uses fewer paths and has a period of range of $10-70 \mathrm{~s}$ rather than $5--70 \mathrm{~s}$. We use surf 96 to calculate $V_{\mathrm{sh}}$ values from Love wave group velocity pseudo-dispersion curves at the same points that we use in this study. At each of these points we calculate $\xi=\left(V_{\mathrm{sh}} / V_{\mathrm{sv}}\right)^{2}$. These results (Fig. 8) show that the mid-crust ( $\sim 20-50 \mathrm{~km})$ beneath the Tibetan Plateau and the Pamirs exhibits strong radial anisotropy with $V_{\text {sh }}>V_{\text {sv }}$ throughout the region.

The strongest radial anisotropy ( $\sim 20-25 \%$, values of $\xi$ of 1.45 1.6) is observed in the areas where the lowest velocities in the low velocity layer are also observed. Like Agius \& Lebedev (2014), we find the strongest anisotropy in west Tibet, although the anisotropy is found to be stronger in our study, and we observe relatively strong anisotropy in northeast Tibet, while this is where anisotropy is low or absent in their study. In eastern Tibet, where our study area coincides with that of Xie et al. (2013), we observe a broadly similar pattern in the depth and lateral extent of the anisotropy, in particular the decrease in anisotropy at the northern edge of the Tibetan Plateau. The magnitude of anisotropy we observe is larger than that calculated by Xie et al. (2013). Forward modelling suggests that our method may overestimate the magnitude of $\xi$, but the presence and depth of anisotropy are robust. This evidence strongly supports radial anisotropy as a major cause of the low velocity layer observed in Tibet. It is probable that the low velocity layer observed is a result of temperature, melt, fluids and anisotropy in varying degrees in different parts of the Tibetan Plateau and the Pamirs, thus accounting for the variability in the properties of the layer. Fully understanding this variability will require the further detailed mapping of crustal radial anisotropy using more recently acquired seismic data, as well as better estimates of heat flow and age of crustal thickening across the region. Irrespective of the exact cause, the mechanisms that have produced this ubiquitous 

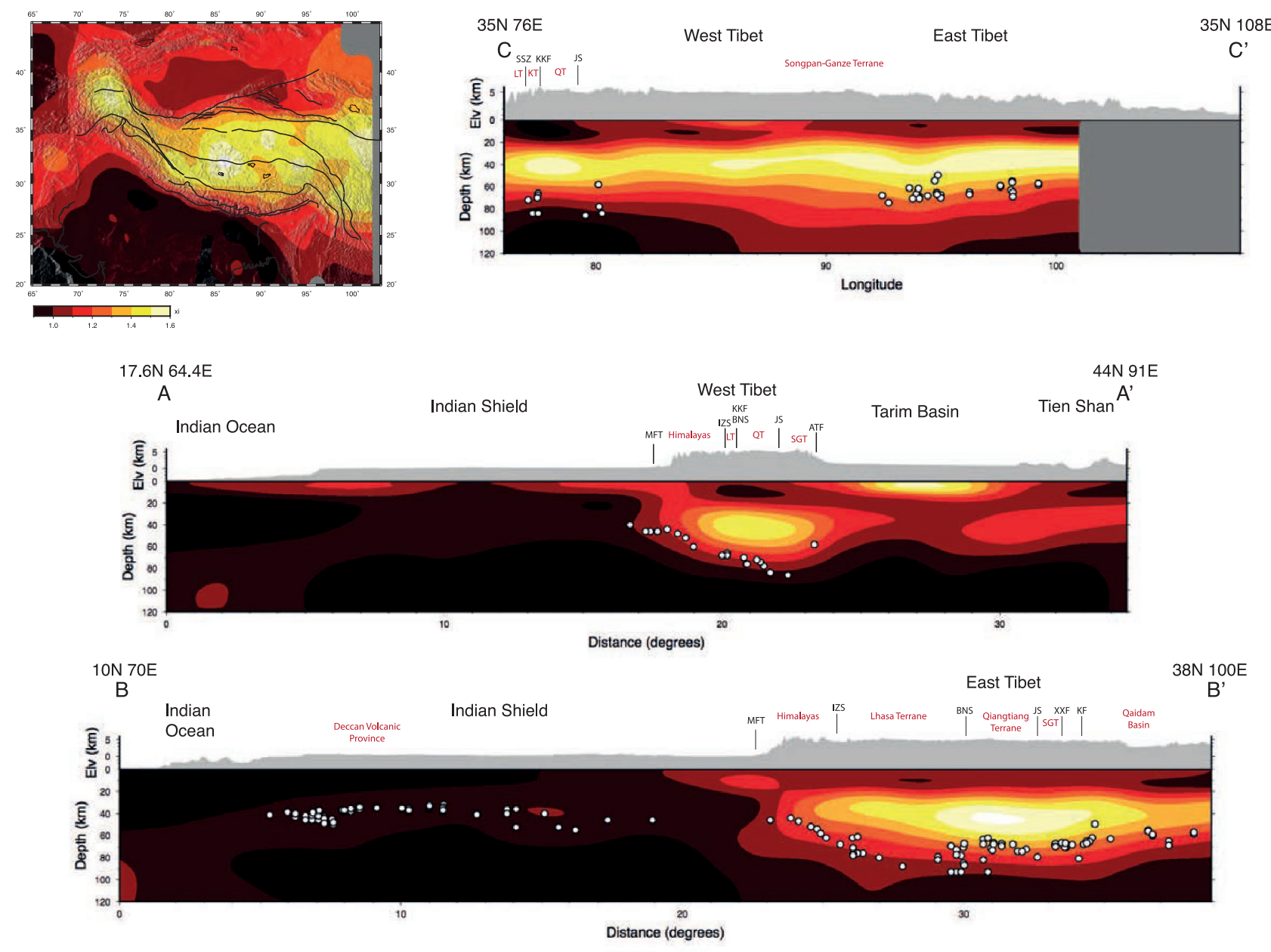

Figure 8. (a) Radial anisotropy map at $30 \mathrm{~km}$ depth and (b-d) cross-sections across the Tibetan Plateau. The map and cross-sections are plotted at the same scale. White circles mark the depths of the Moho from joint surface wave dispersion-receiver function inversion in this study, additional unpublished Moho depth estimates determined in the same manner and previously published Moho depth estimates from Gilligan et al. (2015), within 200 km of the line of section.

low velocity layer throughout Tibet would be in agreement with the presence of a weaker layer in the mid-crust. Such a layer is an important component in models that argue that deformation is occurring due to flow in the mid-crust (e.g. Jamieson et al. 2004), and thus our results are supportive of such models.

\section{CONCLUSIONS}

The extremely dense path coverage afforded by the fundamental mode Rayleigh wave dispersion measurements used in this study has allowed for high-resolution group velocity maps of Tibet and India to be produced. These maps are able to resolve smaller scale features more faithfully than previous studies due to a denser and more uniform path coverage. They are consistent with known geological features, such as sedimentary basins and cratons.

The velocity change at the Moho, together with the elevated shear velocities in the upper mantle observed across all of west Tibet, shows that Indian lithosphere is likely present beneath all of west Tibet. This may not be the case for much of eastern Tibet.

We observe a velocity decrease in the mid-crust between depths of $\sim 20$ and $40 \mathrm{~km}$ across all of the Tibetan Plateau north of the IndusZangbo Suture. In this layer, shear velocities are observed to decease to less than $3.4 \mathrm{~km} \mathrm{~s}^{-1}$ everywhere. The thickness of this layer, the lowest velocity in the layer and the degree of velocity reduction vary across the region, indicating that the causes of the low velocities may themselves be variable. The layer is thickest and has the largest decrease in velocity relative to layers above in the Qiangtang terrane in west-central Tibet and in the Songpan-Ghanze terrane in northeast Tibet. Melt, fluids, elevated temperatures and radial anisotropy are all reasonable candidates to producing a velocity decrease of the magnitude we observe. Temperatures may increase due to radiogenic heating due to crustal thickening (Jamieson et al. 1998; McKenzie \& Priestley 2008) or due to heating from asthenospheric material beneath a thinned lithosphere (e.g. Owens \& Zandt 1997; Chung et al. 2005). Given the observation of fast shear velocities in the uppermost mantle beneath west Tibet it seems unlikely that the low velocities in this area are a product of asthenospheric heating. The correspondence between areas of high radial anisotropy and large velocity decreases in this region indicate that anisotropy may play a much more important role in the development of the low velocity layer in this region. Irrespective of the exact cause, the presence of a ubiquitous low velocity layer throughout Tibet supports the idea that deformation is likely occurring due to flow in the mid-crust (e.g. Jamieson et al. 2004). 


\section{ACKNOWLEDGEMENTS}

We thank Michael Ritzwoller and two anonymous reviewers for constructive comments that have helped improve the manuscript. The majority of the seismic data used in this study were downloaded from IRIS DMC. Data for the NGRI stations in India were provided by S.S. Rai, and Zahid Rafi provided the PMD Pakistan data. Kajal Borah provided the ambient noise cross-correlations for the Uttaranchal network. Figures were prepared using Generic Mapping Tools (GMT) software (Wessel et al. 2013). We thank Robert Herrmann for making the Computer Programs in Seismology freely available.

\section{REFERENCES}

Acton, C., Priestley, K., Gaur, V. \& Rai, S., 2010. Group velocity tomography of the Indo-Eurasian collision zone, J. geophys. Res., 115(B12), doi:10.1029/2009JB007021.

Acton, C., Priestley, K., Mitra, S. \& Gaur, V., 2011. Crustal structure of the Darjeeling-Sikkim Himalaya and southern Tibet, Geophys. J. Int., 184(2), 829-852.

Agius, M.R. \& Lebedev, S., 2013. Tibetan and Indian lithospheres in the upper mantle beneath Tibet: evidence from broadband surface-wave dispersion, Geochem. Geophys. Geosyst., 14(10), 4260-4281.

Agius, M.R. \& Lebedev, S., 2014. Shear-velocity structure, radial anisotropy and dynamics of the Tibetan crust, Geophys. J. Int., 199(3), 1395-1415.

Agius, M.R. \& Lebedev, S., 2017. Complex, multilayered azimuthal anisotropy beneath Tibet: evidence for co-existing channel flow and pureshear crustal thickening, Geophys. J. Int., 210(3), 1823-1844.

Alam, M., Alam, M.M., Curray, J.R., Chowdhury, M.L.R. \& Gani, M.R., 2003. An overview of the sedimentary geology of the Bengal Basin in relation to the regional tectonic framework and basin-fill history, Sedimentary Geol., 155(3), 179-208.

Argand, E., 1924. La tectonique de l'Asie, in 13th Int. Geol. Cong., Comptes Rendus, Brussels, Vol. 5, 171-372.

Bao, X. et al., 2015. Two crustal low-velocity channels beneath SE Tibet revealed by joint inversion of Rayleigh wave dispersion and receiver functions, Earth planet. Sci. Lett., 415, 16-24.

Barron, J. \& Priestley, K., 2009. Observations of frequency-dependent Sn propagation in Northern Tibet, Geophys. J. Int., 179(1), 475-488.

Bensen, G., Ritzwoller, M., Barmin, M., Levshin, A., Lin, F., Moschetti, M., Shapiro, N. \& Yang, Y., 2007. Processing seismic ambient noise data to obtain reliable broad-band surface wave dispersion measurements, Geophys. J. Int., 169(3), 1239-1260.

Borah, K., Rai, S., Prakasam, K., Gupta, S., Priestley, K. \& Gaur, V., 2014. Seismic imaging of crust beneath the Dharwar Craton, India, from ambient noise and teleseismic receiver function modelling, Geophys. J. Int., 197, 748-767.

Brandon, C. \& Romanowicz, B., 1986. A no-lid zone in the central ChangThang platform of Tibet: Evidence from pure path phase velocity measurements of long period Rayleigh waves, J. geophys. Res., 91(B6), 65476564.

Brown, L. et al., 1996. Bright spots, structure, and magmatism in southern Tibet from INDEPTH seismic reflection profiling, Science, 274, 16881690.

Caldwell, W.B., Klemperer, S.L., Rai, S.S. \& Lawrence, J.F., 2009. Partial melt in the upper-middle crust of the northwest Himalaya revealed by Rayleigh wave dispersion, Tectonophysics, 477(1), 58-65.

Christensen, N.I., 1979. Compressional wave velocities in rocks at high temperatures and pressures, critical thermal gradients, and crustal lowvelocity zones, J. geophys. Res., 84(B12), 6849-6857.

Chung, S.-L. et al., 2005. Tibetan tectonic evolution inferred from spatial and temporal variations in post-collisional magmatism, Earth-Sci. Rev., 68(3), 173-196.

Chun, K.-Y. \& Yoshii, T., 1977. Crustal structure of the Tibetan Plateau: A surface-wave study by a moving window analysis, Bull. seism. Soc. Am., 67(3), 735-750.
Cotte, N., Pedersen, H., Campillo, M., Mars, J., Ni, J., Kind, R., Sandvol, E. \& Zhao, W., 1999. Determination of the crustal structure in southern Tibet by dispersion and amplitude analysis of Rayleigh waves, Geophys. J. Int., 138(3), 809-819.

Debayle, E. \& Ricard, Y., 2013. Seismic observations of large-scale deformation at the bottom of fast-moving plates, Earth planet. Sci. Lett., 376, 165-177.

Deng, Y., Shen, W., Xu, T. \& Ritzwoller, M.H., 2015. Crustal layering in northeastern Tibet: A case study based on joint inversion of receiver functions and surface wave dispersion, J. geophys. Int., 203(1), 692-706.

Desheng, L., Digang, L., Chengzao, J., Gang, W., Qizhi, W. \& Dengfa, H., 1996. Hydrocarbon accumulations in the Tarim basin, China, AAPG Bull., 80(10), 1587-1603.

Dricker, I. \& Roecker, S., 2002. Lateral heterogeneity in the upper mantle beneath the Tibetan plateau and its surroundings from SS-S travel time residuals, J. geophys. Res., 107(B11), doi:10.1029/2001JB000797.

Dziewonski, A., Bloch, S. \& Landisman, M., 1969. A technique for the analysis of transient seismic signals, Bull. seism. Soc. Am., 59(1), 427444.

Gilligan, A., Priestley, K.F., Roecker, S.W., Levin, V. \& Rai, S., 2015. The crustal structure of the western Himalayas and Tibet, J. geophys. Res., 120(5), 3946-3964.

Gilligan, A., Roecker, S.W., Priestley, K.F. \& Nunn, C., 2014. Shear velocity model for the Kyrgyz Tien Shan from joint inversion of receiver function and surface wave data, Geophys. J. Int., 199(1), 480-498.

Griot, D.-A., Montagner, J.-P. \& Tapponnier, P., 1998. Phase velocity structure from Rayleigh and Love waves in Tibet and its neighboring regions, J. geophys. Res., 103(B9), 21215-21232.

Guo, Z., Gao, X., Yao, H., Li, J. \& Wang, W., 2009. Midcrustal lowvelocity layer beneath the central Himalaya and southern Tibet revealed by ambient noise array tomography, Geochem. Geophys. Geosyst., 10(5), doi:10.1029/2009GC002458.

Gupta, S., Rai, S., Prakasam, K., Srinagesh, D., Bansal, B., Chadha, R., Priestley, K. \& Gaur, V., 2003. The nature of the crust in southern India: implications for Precambrian crustal evolution, Geophys. Res. Lett., 30(8), doi:10.1029/2002GL016770.

Hacker, B., Ritzwoller, M. \& Xie, J., 2014. Partially melted, mica-bearing crust in Central Tibet, Tectonics, 33(7), 1408-1424.

Hacker, B.R., Gnos, E., Ratschbacher, L., Grove, M., McWilliams, M., Sobolev, S.V., Wan, J. \& Zhenhan, W., 2000. Hot and dry deep crustal xenoliths from Tibet, Science, 287(5462), 2463-2466.

Herrmann, R.B., 2004. Computer Programs in Seismology, St. Louis University.

Houseman, G.A., McKenzie, D.P. \& Molnar, P., 1981. Convective instability of a thickened boundary layer and its relevance for the thermal evolution of continental convergent belts, J. geophys. Res., 86(B7), 6115-6132.

Jamieson, R.A., Beaumont, C., Fullsack, P. \& Lee, B., 1998. Barrovian regional metamorphism: Where's the heat? Geol. Soc. Lond. Spec. Publ., 138(1), 23-51.

Jamieson, R.A., Beaumont, C., Medvedev, S. \& Nguyen, M.H., 2004. Crustal channel flows: 2 . Numerical models with implications for metamorphism in the Himalayan-Tibetan orogen, J. geophys. Res., 109(B6) doi:10.1029/2003JB002811.

Jiang, C., Yang, Y. \& Zheng, Y., 2014. Penetration of mid-crustal low velocity zone across the Kunlun Fault in the NE Tibetan Plateau revealed by ambient noise tomography, Earth planet. Sci. Lett., 406, 81-92.

Kaila, K. \& Krishna, V., 1992. Deep seismic sounding studies in India and major discoveries, Curr. Sci., 62, 117-154.

Kennett, B., Engdahl, E. \& Buland, R., 1995. Constraints on seismic velocities in the Earth from traveltimes, Geophys. J. Int., 122(1), 108-124.

Kind, R. et al., 2002. Seismic images of crust and upper mantle beneath Tibet: evidence for Eurasian plate subduction, Science, 298(5596), 12191221.

Klemperer, S.L., 2006. Crustal flow in Tibet: geophysical evidence for the physical state of Tibetan lithosphere, and inferred patterns of active flow, Geol. Soc. Lond. Spec. Publ., 268(1), 39-70.

Laske, G. \& Masters, G., 1997. A global digital map of sediment thickness, EOS, Trans. Am. geophys. Un., 78(78), F483. 
Levshin, A., Pisarenko, V.F. \& Pogrebinsky, G.A., 1972. Frequency-time analysis of oscillations, Ann. Geophys., 28, 211-218.

Levshin, A. \& Ritzwoller, M., 2001. Automated detection, extraction, and measurement of regional surface waves, in Monitoring the Comprehensive Nuclear-Test-Ban Treaty: Surface Waves, pp. 1531-1545, Springer.

Ligorría, J.P. \& Ammon, C.J., 1999. Iterative deconvolution and receiverfunction estimation, Bull. seism. Soc. Am., 89(5), 1395-1400.

Li, H., Shen, Y., Huang, Z., Li, X., Gong, M., Shi, D., Sandvol, E. \& Li, A., 2014. The distribution of the mid-to-lower crustal low-velocity zone beneath the northeastern Tibetan Plateau revealed from ambient noise tomography, J. geophys. Res., 119(3), 1954-1970.

Li, H., Su, W., Wang, C.-Y. \& Huang, Z., 2009. Ambient noise Rayleigh wave tomography in western Sichuan and eastern Tibet, Earth planet. Sci. Lett., 282(1-4), 201-211.

Litvinovsky, B.A., Steele, I.M. \& Wickham, S.M., 2000. Silicic magma formation in overthickened crust: melting of charnockite and leucogranite at 15, 20 and $25 \mathrm{kbar}$, J.Petrol., 41(5), 717-737.

Makovsky, Y., Klemperer, S.L., Ratschbacher, L., Brown, L.D., Li, M., Zhao, W. \& Meng, F., 1996. INDEPTH wide-angle reflection observation of Pwave-to-S-wave conversion from crustal bright spots in Tibet, Science, 274(5293), 1690-1692.

McKenzie, D. \& Priestley, K., 2008. The influence of lithospheric thickness variations on continental evolution, Lithos, 102(1), 1-11.

McKenzie, D. \& Priestley, K., 2016. Speculations on the formation of cratons and cratonic basins, Earth planet. Sci. Lett., 435, 94-104.

McNamara, D., Walter, W., Owens, T. \& Ammon, C., 1997. Upper mantle velocity structure beneath the Tibetan Plateau from Pn travel time tomography, J. geophys. Res., 102(B1), 493-505.

Mitra, S., Priestley, K., Acton, C. \& Gaur, V.K., 2011. Anomalous surface wave dispersion and the enigma of "continental-like" structure for the Bay of Bengal, J. Asian Earth Sci., 42(6), 1243-1255.

Mitra, S., Priestley, K., Bhattacharyya, A.K. \& Gaur, V., 2005. Crustal structure and earthquake focal depths beneath northeastern India and southern Tibet, Geophys. J. Int., 160(1), 227-248.

Mitra, S., Priestley, K., Gaur, V., Rai, S. \& Haines, J., 2006. Variation of Rayleigh wave group velocity dispersion and seismic heterogeneity of the Indian crust and uppermost mantle, J. geophys. Int., 164(1), 88-98.

Molnar, P., 1990. S-wave residuals from earthquakes in the Tibetan region and lateral variations in the upper mantle, Earth planet. Sci. Lett., 101(1), $68-77$.

Molnar, P., England, P. \& Martinod, J., 1993. Mantle dynamics, uplift of the Tibetan Plateau, and the Indian monsoon, Rev. Geophys., 31(4), 357-396.

Nelson, K.D. et al., 1996. Partially molten middle crust beneath southern Tibet: synthesis of project INDEPTH results, Science, 274(5293), 16841688.

Ni, J. \& Barazangi, M., 1983. High-frequency seismic wave propagation beneath the Indian Shield, Himalayan Arc, Tibetan Plateau and surrounding regions: high uppermost mantle velocities and efficient $\mathrm{Sn}$ propagation beneath Tibet, Geophys. J. Int., 72(3), 665-689.

Nunn, C., Roecker, S.W., Priestley, K.F., Liang, X. \& Gilligan, A., 2014. Joint inversion of surface waves and teleseismic body waves across the Tibetan collision zone: the fate of subducted Indian lithosphere, Geophys. J. Int., 198(3), 1526-1542.

Nábělek, J. et al., 2009. Underplating in the Himalaya-Tibet collision zone revealed by the Hi-CLIMB experiment, Science, 325(5946), 1371-1374.

Owens, T.J. \& Zandt, G., 1997. Implications of crustal property variations for models of Tibetan plateau evolution, Nature, 387(6628), 37-43.

Pilidou, S., Priestley, K., Gudmundsson, O. \& Debayle, E., 2004. Upper mantle S-wave speed heterogeneity and anisotropy beneath the North Atlantic from regional surface wave tomography: the Iceland and Azores plumes, Geophys. J. Int., 159(3), 1057-1076.

Priestley, K., Debayle, E., McKenzie, D. \& Pilidou, S., 2006. Upper mantle structure of eastern Asia from multimode surface waveform tomography, J. geophys. Res., 111(B10), doi:10.1029/2005JB004082.

Priestley, K., Jackson, J. \& McKenzie, D., 2008. Lithospheric structure and deep earthquakes beneath India, the Himalaya and southern Tibet, Geophys. J. Int., 172(1), 345-362.
Priestley, K. \& McKenzie, D., 2006. The thermal structure of the lithosphere from shear wave velocities, Earth planet. Sci. Lett., 244(1), 285-301.

Priestley, K. \& McKenzie, D., 2013. The relationship between shear wave velocity, temperature, attenuation and viscosity in the shallow part of the mantle, Earth planet. Sci. Lett., 381, 78-91.

Rai, S., Priestley, K., Gaur, V., Mitra, S., Singh, M. \& Searle, M., 2006. Configuration of the Indian Moho beneath the NW Himalaya and Ladakh, Geophys. Res. Lett., 33(15), doi:10.1029/2006GL026076.

Rai, S., Priestley, K., Suryaprakasam, K., Srinagesh, D., Gaur, V. \& Du, Z., 2003. Crustal shear velocity structure of the south Indian shield, $J$. geophys. Res., 108(B2), doi:10.1029/2002JB001776.

Rapine, R., Tilmann, F., West, M., Ni, J. \& Rodgers, A., 2003. Crustal structure of northern and southern Tibet from surface wave dispersion analysis, J. geophys. Res., 108(B2) doi:10.1029/2001JB000445.

Rham, D., 2009, The crust and uppermost mantle structure of the Iranian Plateau, $P h D$ thesis, University of Cambridge.

Ritzwoller, M.H., Shapiro, N.M., Barmin, M.P. \& Levshin, A.L., 2002. Global surface wave diffraction tomography, J. geophys. Res., 107(B12), doi:10.1029/2002JB001777.

Sass, P., Ritter, O., Ratschbacher, L., Tympel, J., Matiukov, V., Rybin, A. \& Batalev, V.Y., 2014. Resistivity structure underneath the Pamir and Southern Tian Shan, Geophys. J. Int., 198(1), 564-579.

Searle, M.P., Elliott, J., Phillips, R. \& Chung, S.-L., 2011. Crustallithospheric structure and continental extrusion of Tibet, J. geol. Soc., 168(3), 633-672.

Shapiro, N. \& Ritzwoller, M., 2002. Monte-Carlo inversion for a global shear-velocity model of the crust and upper mantle, Geophys. J. Int., 151(1), 88-105.

Shapiro, N.M., Ritzwoller, M.H., Molnar, P. \& Levin, V., 2004. Thinning and flow of Tibetan crust constrained by seismic anisotropy, Science, 305(5681), 233-236.

Sun, X. et al., 2014. Crustal structure beneath SE Tibet from joint analysis of receiver functions and Rayleigh wave dispersion, Geophys. Res. Lett., 41(5), 1479-1484.

Unsworth, M. et al., 2004. Crustal and upper mantle structure of northern Tibet imaged with magnetotelluric data, J. geophys. Res., 109(B2), doi:10.1029/2002JB002305.

Wei, W. et al., 2001. Detection of widespread fluids in the Tibetan crust by magnetotelluric studies, Science, 292(5517), 716-719.

Wessel, P., Smith, W.H.F., Scharroo, R., Luis, J.F. \& Wobbe, R., 2013. Generic Mapping Tools: Improved version released, EOS Trans. AGU, 94, 409-410.

Wittlinger, G. et al., 2004. Teleseismic imaging of subducting lithosphere and Moho offsets beneath western Tibet, Earth planet. Sci. Lett., 221(1), $117-130$.

Xie, J., Ritzwoller, M.H., Shen, W. \& Wang, W., 2017. Crustal anisotropy across eastern Tibet and surroundings modeled as a depth-dependent tilted hexagonally symmetric medium, Geophys. J. Int., 209(1), 466-491.

Xie, J., Ritzwoller, M.H., Shen, W., Yang, Y., Zheng, Y. \& Zhou, L., 2013. Crustal radial anisotropy across eastern Tibet and the western Yangtze craton, J. geophys. Res., 118(8), 4226-4252.

Yang, Y., Ritzwoller, M.H., Zheng, Y., Shen, W., Levshin, A.L. \& Xie, Z., 2012. A synoptic view of the distribution and connectivity of the mid-crustal low velocity zone beneath Tibet, J. geophys. Res., 117(B4), doi:10.1029/2011JB008810.

Zhang, Z., Deng, Y., Teng, J., Wang, C., Gao, R., Chen, Y. \& Fan, W., 2011. An overview of the crustal structure of the Tibetan plateau after 35 years of deep seismic soundings, $J$. Asian Earth Sci., 40(4), 977-989.

Zhang, Z. et al., 2014. The Moho beneath western Tibet: shear zones and eclogitization in the lower crust, Earth planet. Sci. Lett., 408, 370-377.

Zhao, W., Nelson, K., Che, J., Quo, J., Lu, D., Wu, C. \& Liu, X., 1993. Deep seismic reflection evidence for continental underthrusting beneath southern Tibet, Nature, 366(6455), 557-559.

Zhu, L., Owens, T.J. \& Randall, G.E., 1995. Lateral variation in crustal structure of the northern Tibetan Plateau inferred from teleseismic receiver functions, Bull. seism. Soc. Am., 85(6), 1531-1540. 


\section{SUPPORTING INFORMATION}

Supplementary data are available at $G J I$ online.

Figure S1. (a) Paths between stations and earthquakes used to generate path average Rayleigh wave dispersion curves. Purple lines are new paths (4424), blue lines are from Gilligan et al. (2014) (2268), light blue lines are from Nunn et al. (2014) (1529) and black lines are from Acton et al. (2010) and Rham (2009) (7227). Not all periods have the same path coverage. (b) Paths between stations used to generate path average. Rayleigh wave dispersion curves from ambient noise data. Not all periods have the same path coverage. (c) Frequency distribution of the clustered and unclustered data used in this study. Data at $5 \mathrm{~s}$ are only from the new paths and Gilligan et al. (2014), and data at 8 and $12 \mathrm{~s}$ are only from new paths, Gilligan et al. (2014) and Nunn et al. (2014).

Figure S2. Rayleigh wave group velocity sensitivity kernels for periods 5-70 s for the velocity model obtained at $28^{\circ} \mathrm{N}, 87^{\circ} \mathrm{E}$, typical of that for most of Tibet
Figure S3. Optimized Voroni diagrams for the paths in the 10, 20, 40 and $70 \mathrm{~s}$ inversions. Initial cell size is $1^{\circ}$.

Figure S4. Forward modelling test for the velocity model obtained at $34^{\circ} \mathrm{N}, 80^{\circ} \mathrm{E}$ to demonstrate that the inversion results from the Rayleigh wave group velocity dispersion curves have little sensitivity below $120 \mathrm{~km}$ depth. A significantly slower upper mantle does not alter the fit to the dispersion curve

Figure S5. Resulting checkerboards computed from synthetic traveltimes through input models of $2^{\circ}, 3^{\circ}, 5^{\circ}$ and $7.5^{\circ}$ checkers for the same paths as used in the tomography for $10 \mathrm{~s}$ Rayleigh wave group velocity measurements.

Please note: Oxford University Press is not responsible for the content or functionality of any supporting materials supplied by the authors. Any queries (other than missing material) should be directed to the corresponding author for the paper. 